\title{
Insights into the Processing of Recycled Carbon Fibers via Injection Molding Compounding
}

\author{
Jochen Wellekötter ${ }^{1, *(\mathbb{C}}$, Julia Resch ${ }^{1, *}$, Stephan Baz ${ }^{2}$, Götz Theo Gresser ${ }^{2}$ and Christian Bonten ${ }^{1}$ \\ 1 Institut für Kunststofftechnik (IKT), University of Stuttgart, Pfaffenwaldring 32, 70569 Stuttgart, Germany; \\ christian.bonten@ikt.uni-stuttgart.de \\ 2 Deutsche Institute für Textil- und Faserforschung Denkendorf (DITF), Körschtalstraße 26, \\ 73770 Denkendorf, Germany; Stephan.Baz@ditf.de (S.B.); goetz.gresser@ditf.de (G.T.G.) \\ * Correspondence: jochen.wellekoetter@ikt.uni-stuttgart.de (J.W.); julia.resch@ikt.uni-stuttgart.de (J.R.); \\ Tel.: +49-711-685-62864 (J.W.); +49-711-685-62841 (J.R.)
}

Received: 16 September 2020; Accepted: 20 October 2020; Published: 27 October 2020

check for updates

\begin{abstract}
Although fiber-reinforced plastics combine high strength and stiffness with being lightweight, major difficulties arise with high volume production and the return of manufactured parts back into the cycle of materials at the end of their lifecycles. In a novel approach, structural parts were produced from recycled material while utilizing the so-called injection molding compounding process. Recycled fibers and recycled polyamide matrix material were used by blending carbon and matrix fibers into a sliver before processing. Injection molding was then used to produce long fiber-reinforced parts through a direct fiber feed system. Recycled matrix granules were incorporated into the injection molding process by means of an injection molding compounder to investigate their influences on the mechanical properties of the parts. The findings show that the recycled fibers and matrix perform well in standardized tests, although fiber length and fiber content vary significantly and remain below expectations.
\end{abstract}

Keywords: carbon fiber recycling; lightweight design; long fiber-reinforced thermoplastics; parameter-optimization; injection molding compounding

\section{Introduction}

Recycling concepts for fiber-reinforced plastic (FRP) materials should be developed early on to improve the materials' ecological impact [1]. The reuse of FRP is a challenge due to the difficulty in the separation of the materials, and mechanical properties gradually deteriorate owing to the shortening of the reinforcing fibers with each recycling cycle. This affects both the matrix material used and the fibers. A reuse in the form of continuous fibers in the typical composite technologies is not possible, and alternative routes need to be established for the shortened fibers. This phenomenon has been extensively researched and reviewed in various articles. Examples and case studies were summarized by Pimenta et al. [2] and applications of recycled fiber composites were reviewed by Pickering et al. [3]. Oliveux et al. [4] gave examples of how recycled discontinuous fibers compare to virgin material. Pickering [5] analyzed and compared mechanical recycling and the use of fibers as filler materials to pyrolysis processes. This knowledge can nowadays be considered state-of-the-art, as seen in [6].

Since the fiber length deteriorates during recycling, discontinuous fiber technologies are particularly well-suited for the recycling of these materials, as can be seen in [2,3]. However, the material supply into, e.g., the injection molding process, still proves difficult. The authors present a novel method in this study. Here, end-of-life carbon fibers and production waste are blended with recycled thermoplastic matrix fibers and processed into a bundle of aligned fibers, or a "sliver." This sliver can then be processed 
via injection molding. Additionally, the sliver can be further processed into a yarn, which allows for established textile processing methods.

In the case of this study, the sliver was processed in a so-called injection molding compounder (IMC) utilizing a direct fiber feed for fiber incorporation. The injection molding compounder was first introduced by KraussMaffei and enables the direct compounding and injection molding in one process step (single-stage) by combining a twin-screw extruder with an injection molding unit. The IMC and its advantages compared to a two-stage process (separate compounding and injection molding processes) have been proven in various research papers, e.g., by Truckenmüller [7]. Further studies analyzed the use of the IMC, e.g., for the processing of natural fibers [8] or the improvement of resulting fiber length—e.g., see Willems et al. [9] and Wellekötter et al. [10]. It could be shown that the IMC's single-stage process results in longer fibers compared to regular injection molding, thereby improving mechanical properties compared to short-fiber-reinforced thermoplastics [10,11]. The direct fiber feed module draws the fibers into the twin-screw extruder of the IMC near the end of the compounding step, reducing fiber damage and allowing for higher fiber length in the final part.

\subsection{Recycling of Carbon Fibers and Fiber-Reinforced Plastics}

Studies on the development of the composites market (e.g., [12-14]) indicate that the demand for FRP will increase significantly in the near future. For this reason, it is vital to address the challenges of recycling at an early stage. FRPs cannot be easily reused after their lifecycles, nor can they be easily separated, sorted, and treated. In addition, structural damage, such as delamination, is not necessarily visible from the surface, increasing the amount of FRP waste through the replacement of parts to comply with safety regulations.

Thermal recovery (combustion) and thus the recovery of stored energy is possible, although it is extremely unsatisfactory from an ecological and economic point of view, as shown by Meng et al. [1]. However, the reuse of parts from thermoplastic matrices as fillers (see below) in less stressed plastic parts is well-established (examples are summarized in [2,5].

Any other recycling process requires a high degree of purity of the fibers and matrices. Solvolysis (e.g., $[4,15,16]$ and pyrolysis (e.g., $[2,4,17,18]$ (combustion in the absence of oxygen) are already being applied industrially to recover carbon fibers. In pyrolysis, the matrix material is completely burned and energetically recovered, while the carbon fibers have a higher degradation temperature, remain largely inert, and thus retain their properties, albeit with shortened fibers due to previous processing. The fibers also lose their sizing during this process $[2-4,12,18,19]$.

Since the fibers are not infinitely long anymore, but rather have a fiber length distribution depending on the parts which they incorporated, most of the conventional textile processing methods are not applicable. Further processing is limited to reusing these fibers in either compression molding, as reinforcements in the injection molding process, or as fibers for wet- or dry-laid non-wovens [3,18,20-23].

A promising approach is to align the fibers according to the load path and use their full potential as a pre-aligned non-woven (e.g., [23]). Several groups blended recycled carbon fibers with thermoplastic matrix fibers to improve processability and enable reuse in thermoplastic applications as hybrid non-wovens [22], yarns or tapes [24], and filaments for 3D-printing [25].

\subsection{Short Fiber Reinforced Thermoplastics}

In injection molding, fillers enable cost reduction, reduce shrinkage, and can even improve processing properties $[11,26]$. In contrast to fillers, plastics are reinforced to improve the material's mechanical behavior. Reinforcement is achieved with a component that has higher mechanical strength and stiffness compared to the matrix. A sufficiently large length-thickness ratio $(1 / \mathrm{d})$ of the reinforcing component is required for effective reinforcement. Discontinuous fibers are often used for this purpose [11]. 
In addition to a high fiber-matrix adhesion, the fiber length defines the mechanical properties, as illustrated by Thomason [27] and shown in Figure 1. Fiber length influences stiffness, strength, and impact resistance. In general, the longer the fibers in a matrix, the better their mechanical properties [11,27].

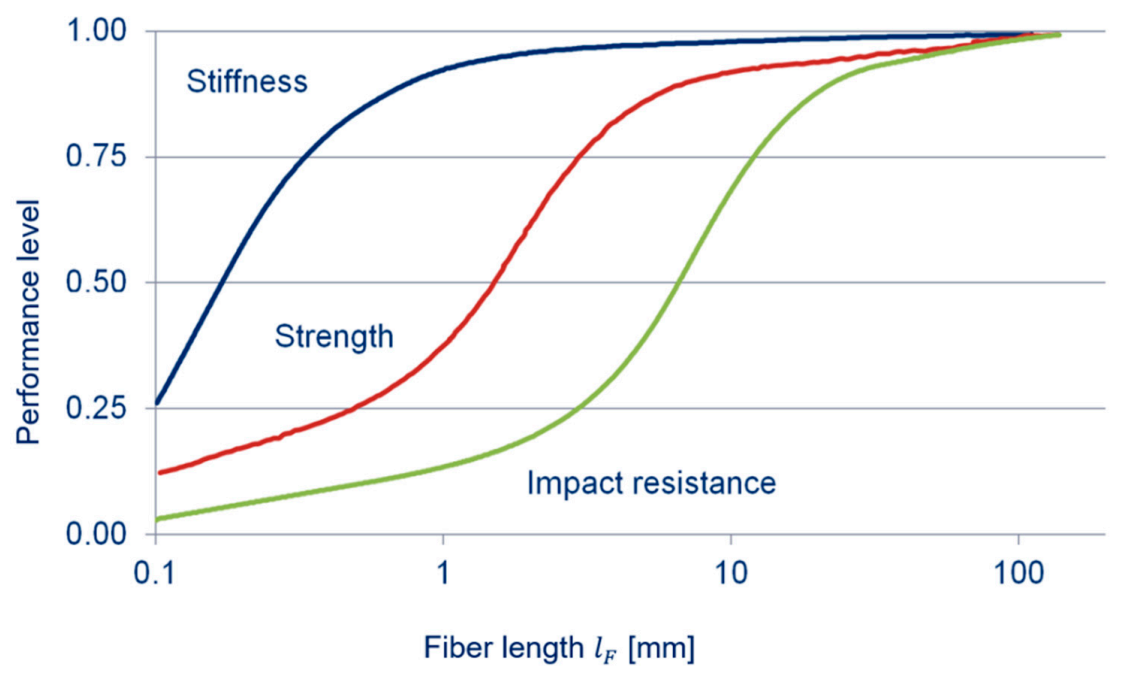

Figure 1. Influences of fiber length on stiffness, tensile strength, and impact strength.

It is, therefore, evident that the longest possible fiber length is desirable for recycled fibers during injection molding to optimize the properties of the new part. In this study, test specimens were produced from different material combinations in a direct processing method (single-stage) [11]. Compared to a regular two-step process, the one-step process allows for longer fibers and improved fiber qualities [11]. This is due to the elimination of repeated melting, the reduction of the fiber path in the extruder, and the lack of a pelletizing step [11]. Both short fibers and endless roving can be introduced into the already fully-plasticized melt via a direct-fiber-feed module. In addition, inexpensive raw materials can be used instead of cost-intensive fiber-reinforced pellets, in combination with large proportions of recycled material.

\subsection{Recycling of Plastics}

The recyclability of plastics is determined by their atomic and structural properties, intermolecular forces, and degree of cross-linking, and by different fillers and reinforcing materials $[11,28]$. Plastics can be recycled in various ways. Material recycling is the reuse of thermoplastic waste by remelting the material and thus creating new products, retaining the macromolecular structure of the polymer. This process is carried out on thermoplastics that have few or no impurities. It is also possible to filter out mixed and contaminated plastics by separation processes before recycling them [29]. If the processing is too expensive because of high levels of impurities or mixing, or if the quality is insufficient after too many recycling cycles, raw-material recycling can be performed. In this case, the macromolecular structure of the polymer is broken down, and the raw material is used for other products. If both methods fail, thermal recycling is an option, i.e., burning the plastic to generate energy $[30,31]$.

Various factors determine the recyclability of thermoplastics and can influence the quality of the products. In addition to possible contamination by dust, paint residues, or mixing with other polymers, a recycling-related degradation of the polymer chains must be taken into account. Multiple uses and processing can lead to thermal, mechanical, hydrolytic, and oxidative degradation. Consequently, recycled plastics have different mechanical properties compared to virgin material. The change in molecular structure also influences the flow behavior of the polymer melt, possibly causing discoloration, burns, or bubbles in the product [32,33]. Important factors in thermal decomposition are the processing 
temperature and residence time. The presence of water can cause hydrolytic decomposition, especially in polycondensation products, such as polyamides. Furthermore, an oxidative decomposition process can occur during processing in an oxygen-rich environment [32,33].

In this study, a polyamide was used as a matrix material. A fraction of recycled material was added for all experiments. The recycling of the polyamide has been extensively analyzed, and a short summary of key insights is given below.

In 2003, the mechanical behavior of different fractions of recycled material $(15,30,50$, and $100 \%)$ of polyamide 6 (PA6) was investigated by Maspoch et al. [30]. The PA6 used for recycling came from fiber production waste and contained $20 \%$ glass particles and $10 \%$ glass fibers. The findings show that a small proportion of only $15 \%$ recycled material significantly reduced the Young's modulus, the maximum tensile stress, and the elongation at break. Similar behavior was shown for bending properties. Furthermore, reductions in the maximum tensile stress and Young's modulus were observed after three recycling cycles.

In 2013, Crespo et al. [34] investigated the effects of recycling PA6. Virgin plastic was recycled five times and analyzed after each cycle on injection-molded test specimens. The test results showed almost constant values for tensile strength and elongation at break. After the fifth cycle, a decrease of less than $2 \%$ in tensile strength and a decrease of $1 \%$ in elongation at break was observed. In comparison, the impact strength was significantly reduced even after the first recycling cycle. After the fifth cycle, the impact strength was reduced by more than 30\% [34].

In another study, Su et al. [35] also investigated the effects of recycled PA6 on the mechanical properties of injection-molded parts; 16 -fold recycling of the plastic was performed. A slight increase in yield stress was observed after each recycling cycle. Similarly to the study by Crespo et al., the elongation at break remained constant until it decreased after the 13th cycle. The flexural strength and modulus increased steadily. The impact strength steadily decreased, similarly to the results from Crespo et al., attributed to the shortening of the molecular chains and the broader distribution of the chain lengths. The originally soft and tough PA6 became hard and brittle with the large number of recycling cycles [35].

Recent studies [36] on the recycling of cast PA6 waste showed that the behavior of the material could be adjusted by compounding. Cast PA6 waste was converted into an extrudable polyamide with suitable additives. Rheological and mechanical analyses revealed that the lubricant leads to higher viscosity and impact strength. Recyclates modified with an oxidizing agent resulted in higher degrees of crystallinity due to the reduced molecular weight and increased stiffness and tensile strength in the final material. Due to the shorter polymer chains, the recyclates had lower viscosities than comparable virgin grades. The material could, therefore, be processed by injection molding.

The authors of this paper further analyzed the recyclability of polyamide by comparing a single-stage and a two-stage process [10]. In the single-stage process, significantly longer fibers and thus better mechanical properties were achieved using direct feed module. The investigations showed that longer fibers could be reached at lower fiber contents. However, the influence of the recycled matrix fraction was negligible.

Pimenta [2] gives a detailed overview and a list of further studies about the incorporation of recycled glass and carbon fibers into the injection molding process (without using recycled matrix material). These studies are, therefore, not be presented here.

\subsection{Aim}

It is evident that the behavior of recycled material cannot yet be fully predicted. The use of an IMC for the recycling of glass fibers has been investigated in a previous study by the authors. There, little influence of the recycling on the mechanical properties could be observed. The authors have not found any further research with respect to recycled (and thus discontinuous) carbon fibers and a single-stage IMC process.

Questions remain: How might recycling carbon fibers be introduced into recycled polyamide grades? How does this process compare to the use of virgin glass fibers? It is assumed that the 
processing of recycled carbon fibers in an IMC leads to increased fiber length and mechanical properties compared to established processes, such as injection molding. Therefore, recycled carbon fibers were introduced into the direct fiber feed module of the IMC and mixed with a recycled polyamide matrix. The fiber content, fiber length, and mechanical behavior were then analyzed to show whether the use of a sliver and an IMC is a feasible approach for the recycling of carbon fibers.

\section{Experimental}

The production of a test specimen in the IMC comprises several process steps. First, a fibrous matrix material is created from recycled material (Section 2.1). These fibers are mixed with recycled carbon fibers (Section 2.2) and processed into a sliver (Section 2.2.3). This sliver is then used as reinforcement for injection molded parts by utilizing a direct fiber feed module of an IMC (Section 2.3).

\subsection{Plastics Recycling}

For the production of various recycling mixtures, a fraction of the plastic is recycled and mixed with virgin material. An industrial-grade PA6 from BASF SE, Ludwigshafen, Germany, with the trade name Ultramid ${ }^{\circledR}$ B3S, was used for all experiments. To exclude a premature degradation reaction of the moisture-sensitive polymer chains, the material was dried for five to six hours at $80{ }^{\circ} \mathrm{C}$. The pre-dried granulate was then processed on an Allrounder 520S 1600-400 injection molding machine from Arburg $\mathrm{GmbH}$, Loßburg, Germany, to form type 1A tension rods in accordance with ISO 527-2.

In the next step, the produced parts were cut into granules with a granulator type FZK 280 from Fellner and Ziegler GmbH, Frankfurt am Main, Germany. The processed recyclate was mixed with virgin material according to the mixing ratios to be tested.

In this study, the different recycling mixtures are labeled based on new material content and recycled material content. Recycling contents of $25 \%$ and $75 \%$ were evaluated. Additionally, each mixture was analyzed with double-recycled material. Double recycling is indicated by a squared recycling content value. For example, a label of "mixture $25 \%$ recy" 2 " identifies a mixture with $75 \%$ new material and $25 \%$ twice-recycled material.

For the production of the hybrid sliver, a fibrous matrix was required in addition to the carbon fibers. To obtain a part made of $100 \%$ recycled material, a multifilament made out of 24 single filaments and a fineness of 100 dtex (110f24) was spun from recycled-polyamide-6 (rPA6) granules on a semi-industrial melt spinning machine. To protect the filaments during further processing and enable stable winding, the sizing SYNTEX 242 from Schill + Seilacher GmbH, Böblingen, Germany, was applied to the multifilament.

The filaments were post-stretched to a single fiber fineness of 4.2 dtex and then crimped in a texturing process with a circular knitting and heat fixation machine from Maschinenfabrik HARRY LUCAS GmbH, Nürnberg, Germany.

The textured multifilament yarns were then cut to a staple fiber length of $61 \mathrm{~mm}$ using an NM-150 cutting converter from Oerlikon Neumag, Neumünster, Germany. The length was selected so that it could be produced with the cutting converter and to match the carbon fibers in terms of length distribution. Uniform fiber lengths are advantageous for textile processing. The manufacturing steps are shown in Figure 2.
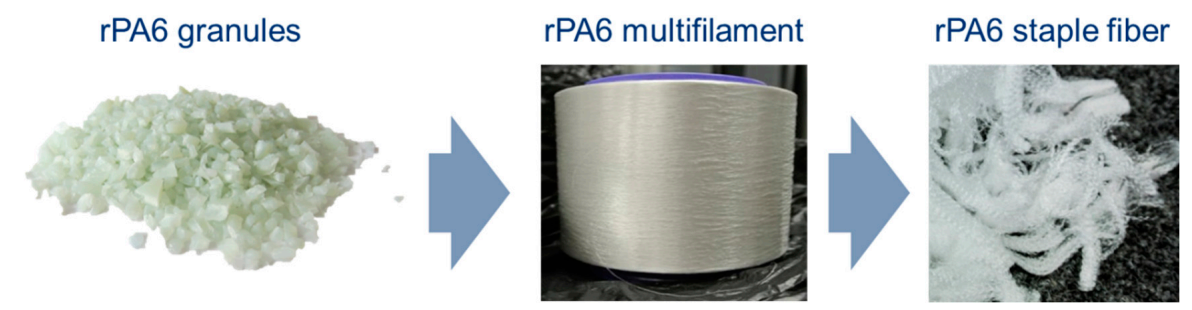

Figure 2. Manufacturing steps of rPA6 staple fibers from rPA6 granules. 


\subsection{Carbon Fiber Recycling}

The formation of a hybrid recycling sliver containing recycled carbon fibers and recycled polyamide matrix fibers spans three processes: opening, blending, and texturizing. The opened fibers are processed to a sliver by means of a card. The pre-opened and blended carbon and matrix fibers are fed into the card with a defined area weight by a feeding chute. The card processes the fiber flocks to single fibers and orients them. Upon the delivery of the card, the formed card web is then merged into a sliver. A detailed overview of the sliver formation is given in Section 2.2.3. First, fiber selection and sizing will be investigated briefly.

\subsubsection{Selection of Fibers}

In principle, recycled carbon fibers can be divided into two categories. The first category describes carbon fibers that are present in the form of production waste (e.g., spool remnants or edge trimmings, roving sections; Table 1, right column) [5]. These carbon fibers have a sizing adapted to the original processing and use. Foreign fibers, e.g., from sewing threads from scrim production, may also be present. The advantage of carbon fibers in the first category is that the sizing is evenly distributed on the fibers, which allows for easier textile processing of the carbon fibers compared to that of fibers without sizing (e.g., less fiber loss). Disadvantages include the presence of partially contained foreign fibers and the unsuitable sizing of the carbon fibers for new applications (e.g., carbon fibers with epoxy sizing to be used in thermoplastic composites).

Table 1. Comparison of the recycled fibers.

\begin{tabular}{|c|c|c|c|}
\hline Type & $\begin{array}{c}\text { Carbiso C60/90 } \\
\text { Pyrolyzed and Cut Rovings }\end{array}$ & $\begin{array}{r}\text { Car } \\
\mathrm{C}\end{array}$ & \\
\hline \multicolumn{4}{|l|}{ Picture } \\
\hline \multirow[t]{2}{*}{ Fiber Fineness } & Sample: & Sample: & 0.83 dtex \\
\hline & $10 \mathrm{~kg}$ batch: & $10 \mathrm{~kg}$ batch: & 0.82 dtex \\
\hline \multirow{2}{*}{ Sizing Amount } & Sample: & Sample: & $1.4 \%$ \\
\hline & $10 \mathrm{~kg}$ batch: & $10 \mathrm{~kg}$ batch: & $0.8 \%$ \\
\hline \multirow{2}{*}{ Tenacity } & $3140 \mathrm{MPa}$ & Sample: & $3100 \mathrm{MPa}$ \\
\hline & $10 \mathrm{~kg}$ batch: & $10 \mathrm{~kg}$ batch: & $3830 \mathrm{MPa}$ \\
\hline \multirow{2}{*}{$\begin{array}{l}\text { Mean Fiber } \\
\text { Length }\end{array}$} & $46.5 \mathrm{~mm}$ & Sample: & $47.5 \mathrm{~mm}$ \\
\hline & $10 \mathrm{~kg}$ batch: & $10 \mathrm{~kg}$ batch: & $41.0 \mathrm{~mm}$ \\
\hline
\end{tabular}

The second category describes carbon fibers that have been dissolved out of the matrix by pyrolysis or solvolysis. Possible sources of carbon fibers in this category are parts at the end of their lifecycles, defective parts, and prepreg waste. The thermal or chemical removal of the matrix results in pure carbon fibers without sizing (Table 1, left column). Without sizing, the carbon fibers no longer adhere to each other, which is beneficial for mixing with matrix fibers. The disadvantage of this property is that, in textile processing, there is a significant amount of fiber-dust formation caused by fiber breakage. An advantage is that, theoretically, both processing and fiber-matrix adhesion can be facilitated by 
applying a sizing adapted to the new application. However, there is currently no available sizing or sizing application process for recycled carbon fibers, and the sizing has to be applied manually.

ELG Carbon Fiber, Coseley, England, offers both original roving sections (production waste) and pyrolyzed carbon fibers. Table 1 shows the results of the investigation of the carbon fibers. There is no significant difference in the fineness-related maximum tensile strength of the carbon fibers before and after pyrolysis.

Table 1 also shows that the use of recycled material leads to fluctuations in material properties. Some carbon fibers have lower individual strengths. In addition, there are large irregularities in the average fiber length and the fiber length distribution within a batch. According to the manufacturer, the fiber length should be in between 60 and $90 \mathrm{~mm}$. This is the case for pyrolyzed carbon fibers. For the non-pyrolyzed production waste, the average fiber length is $47.5 \mathrm{~mm}$ in the best case, well below the manufacturer's specification. The measured value of the average fiber length for the carbon fibers used for sliver production is $41 \mathrm{~mm}$.

\subsubsection{Sizing}

Sizing plays an important role in the recycling and reuse of carbon fibers. Presently, thermoset matrix materials dominate the market, so that a sizing specifically characterized for these materials is often used but not well-suited for thermoplastics. Production waste and residues, in particular, are usually not pre-treated but directly processed, which can lead to considerable difficulties during recycling and a lack of fiber-matrix adhesion in the final part [18].

Fibers from pyrolysis behave even more critically since the sizing is removed in the pyrolysis process [18]. Generally, the "bare" carbon fibers exhibit good fiber-matrix adhesion with PA6 but are difficult to process with the methods used in this study.

To improve the quality and handling of the fibers recovered by pyrolysis, preliminary sizing trials were carried out by the authors. Different sizing compositions were compared. The fibers were also processed without sizing. Samples were produced to analyze the resulting mechanical properties.

In the initial opening and processing trials of the carbon fiber variants, the need for sizing to minimize fiber damage was demonstrated. Significant reductions in fiber length by sizing carbon fibers could be achieved in the fiber preparation process and in fiber opening and sliver production.

The effects of four different sizing systems on the processing of recycling carbon fibers were compared: two industry-grade sizings (Stantex S 6256 PC from Pulcra Chemicals, Geretsried, Germany and Silastol CF1/CF2 from Schill + Seilacher GmbH, Böblingen, Germany), unsized, and original fibers, i.e., roving sections from production waste. Non-woven fabrics with defined carbon-fiber content were produced in a carding process, and the weight yield was recorded as an indicator of the processability of the fibers. Low carbon-fiber content indicates a high loss of fibers due to fiber breakage and entanglement, suggesting worse processing quality.

As shown in Table 2, sizing is necessary for a carding process; otherwise, a product, or "card web," cannot be produced (weight loss without sizing: 100\%). If the fibers are sized manually, however, the losses are kept within limits. Manually sized fibers performed better compared to roving sections. Fibers from rovings need to be separated first, resulting in fiber loss, unlike the "fluffy" structure of fibers from pyrolysis $[2-4,18]$.

Table 2. Carbon fiber weight yield after the carding process.

\begin{tabular}{ccccc}
\hline Sizing & Mass of PA6 in g & $\begin{array}{c}\text { Mass of Carbon } \\
\text { Fibers in } \mathbf{~}\end{array}$ & $\begin{array}{c}\text { Mass after } \\
\text { Processing in } \mathbf{g}\end{array}$ & Loss in \% \\
\hline Silastol CF1/CF2 & 222 & 235 & 331 & 28 \\
Stantex S 6256 PC & 222 & 235 & 349 & 24 \\
Roving Sections & 222 & 235 & 188 & 59 \\
Unsized & 222 & 235 & 0 & 100 \\
\hline
\end{tabular}


After processing, the card web was doubled and compacted to a non-woven-like structure. Two sample plates for each sizing were then produced: the non-wovens were heated to two different temperatures and pressed using a hydraulic parallel press. Microscopic images were then analyzed to determine the fiber-matrix adhesion. An example is given in Figure 3. The examination of the fiber-matrix adhesion was conducted with a scanning electron microscope (SEM). For evaluation, fracture surfaces were generated at temperatures of $-196^{\circ} \mathrm{C}$. All tested sizings showed similar results. Since both commercial sizing types showed a comparable fiber-matrix adhesion and resulted in low fiber losses, one was randomly chosen for further tests in this study. Additionally, roving sections were used for sliver formation trails.

\section{$220^{\circ} \mathrm{C}$}
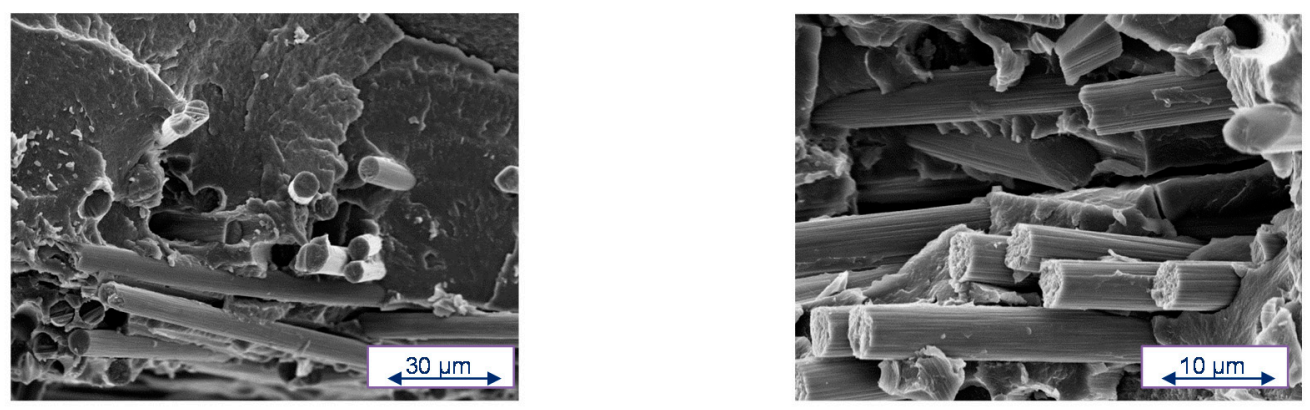

\section{$260^{\circ} \mathrm{C}$}
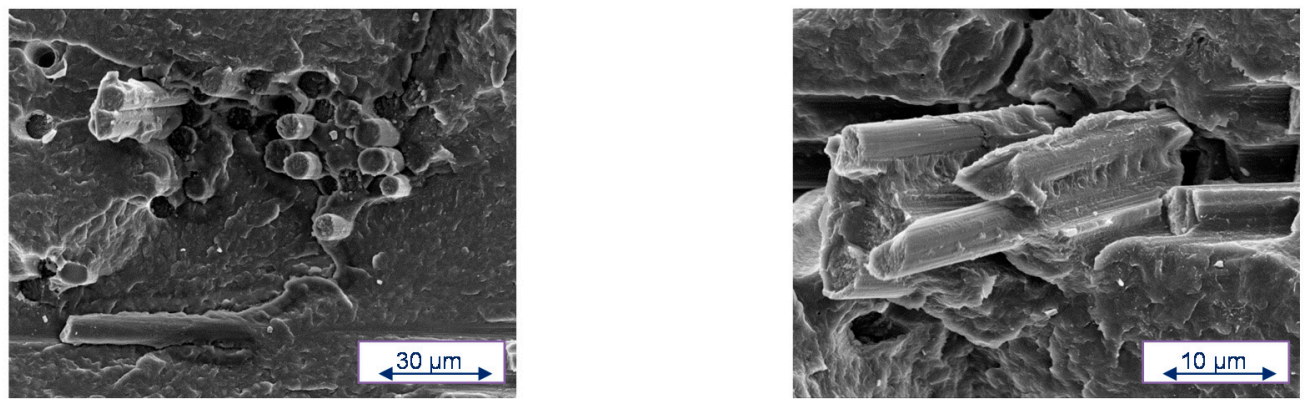

Figure 3. Microscopic images of the sizing Silastol CF1/CF2 after processing at 220 and $260{ }^{\circ} \mathrm{C}$.

The processing of pyrolyzed carbon fibers without sizing proved to be not effective (see Section 1). However, the manual application of an appropriate sizing proved possible. Nonetheless, the processability could not be sufficiently improved, owing to a relatively uneven application. Therefore, roving sections were initially selected as the carbon fiber source for the sliver production.

\subsubsection{Sliver Production}

A sliver is a bundle of fibers that is usually spun into a yarn. In this study the sliver is used as a means to incorporate fibers into the injection molding process via the direct fiber feed module of an IMC. The production steps needed to produce the sliver will be presented in the following.

The first step toward realigning the recycled carbon fibers into a sliver and obtaining an infinite, homogeneous, semi-finished product is the preparation (mixing and opening) of the raw material. The second technological step involves machines that ideally dissolve and orient the fibers, which is called the carding process. Roller cards, like the one in this study, were originally used for processing wool. Wool fibers have low strength and have always been an expensive raw material. For these reasons, processing must be as gentle as possible without major fiber losses. Due to its processing properties, wool fibers are the most comparable textile fibers to carbon fibers.

Figure 4 shows a schematic cross-section of the textile-process chain to produce a sliver out of carbon fibers. The blue line illustrates the material flow through the machine. The general principle of 
the textile conversion of randomly oriented fibers into an aligned semi-finished product like the sliver is to transport, comb, and draw single fibers with metal pins, or "metallic card clothing." The size of the pins decreases as the process progresses to gradually separate and orient the fibers. The mechanical work required for orientation is applied step by step and more gently than if individual fibers are pulled from a large collection at the beginning of the process. Combing processes are generated through different surface speeds of the working elements.

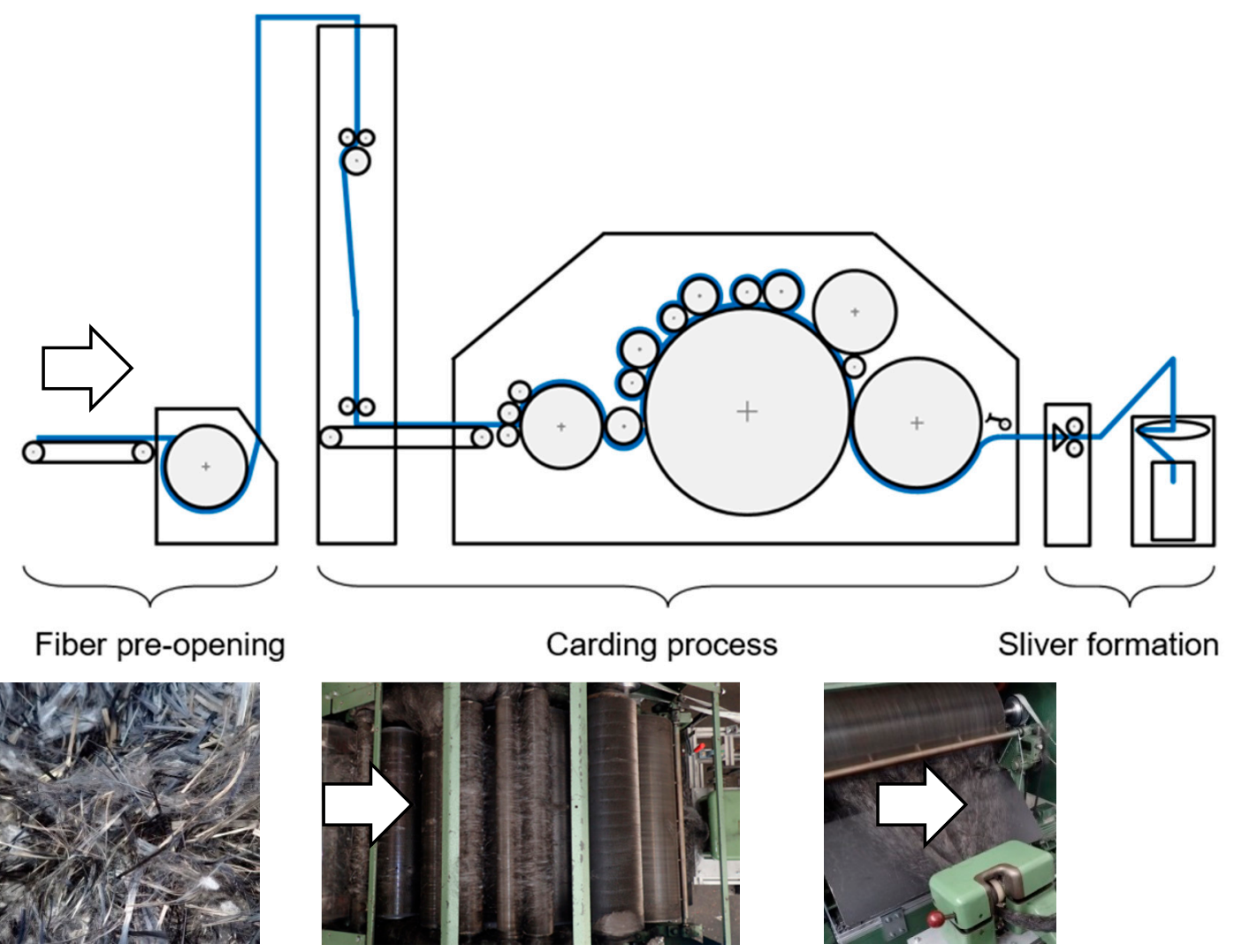

Figure 4. Schematic illustration of the textile process steps used in this study for sliver production (top) and pictures of the material feed (left), the roller card (middle), and the sliver formation (right).

In addition to the orientation of the fibers, the carbon fibers were mixed with the thermoplastic matrix fibers (rPA6) to achieve a homogeneous blend within the sliver. The carding process separates and orients the fibers via mechanical forces, which leads to the breaking of the carbon fibers. At the same time, this separation process results in homogeneous mixing, with the matrix and carbon fibers lying directly next to each other, depending on the fiber diameters of the mixing components.

The process starts with a coarse blend of carbon and rPA6 fibers on an opener from the company Dilo Group, Eberbach, Germany (fiber pre-opening in Figure 4). The processability of the pre-opened fiber blend on the roller card resulted in almost trouble-free further processing with acceptable carbon fiber reduction when the fiber blend was opened twice (two passages, Figure 5). A fiber volume content of $55 \%$ for the sliver was specified as the mixing ratio. To compensate for possible losses during processing, the fiber flocks were mixed with a volume ratio of $65 \%$ carbon fibers to $35 \%$ rPA6. 


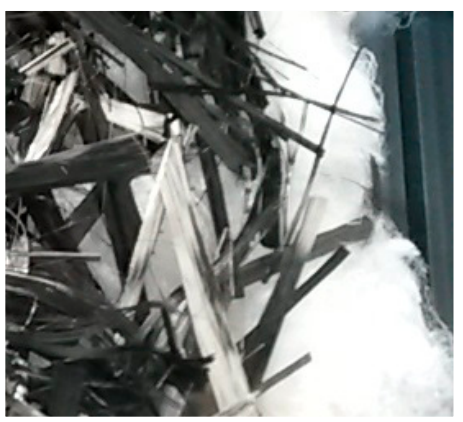

(a) material feeding chute

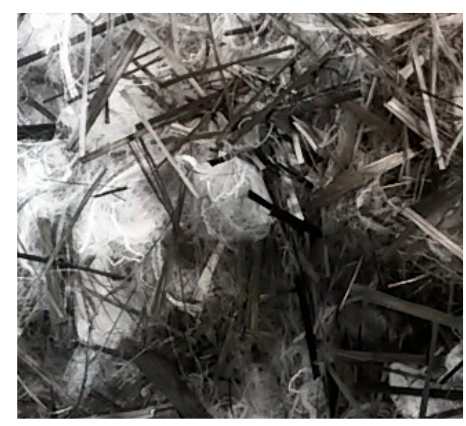

(b) 1st opening step

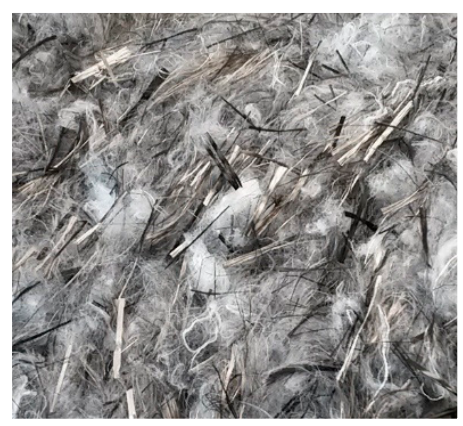

(c) 2nd opening after feeding

Figure 5. Feeding (a) first (b) and second (c) opening and mixing process of carbon (black) and rPA6 (white) fibers.

The pre-opened and mixed fibers are further opened and mixed in the card's feeding chute Type FBK from Trützschler GmbH, Mönchengladbach, Germany. The feeding chute is followed by the carding machine of the company Maschinenfabrik Memmingen, Memmingen, Germany. The output of the card, the card web, is compacted through a cone and stored in a can by means of a can coiler. The sliver take-up and can coiler have been adapted to the card by the authors.

The resulting sliver is shown in Figure 6. On the right side, the oriented carbon fibers within the sliver and the homogenous blend of black carbon and white matrix fibers (grey) can be seen.

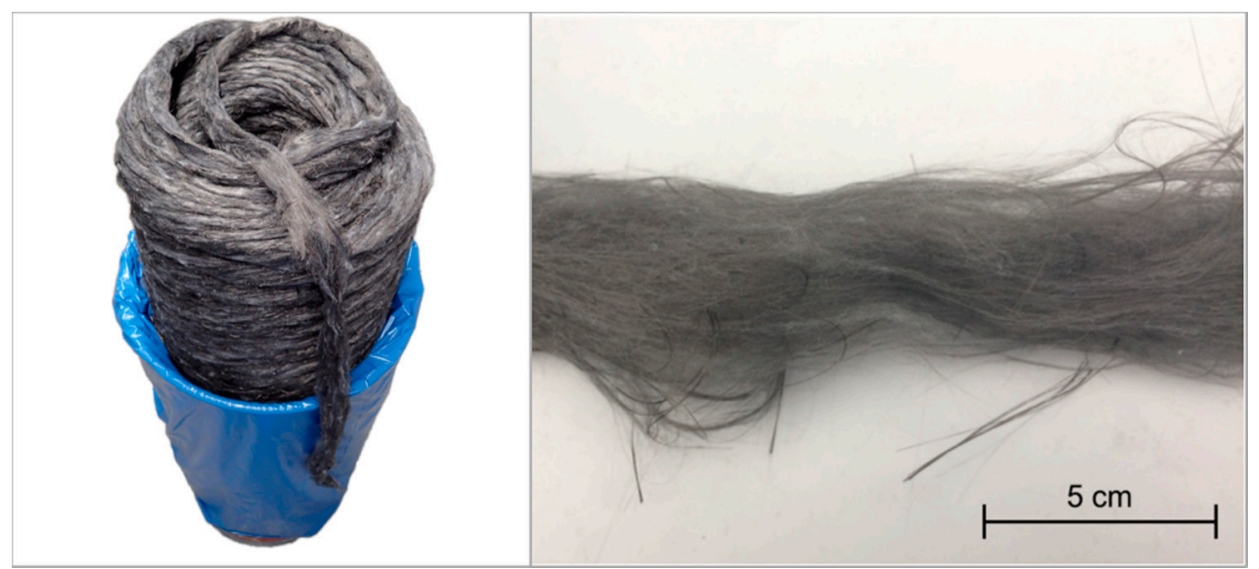

Figure 6. Sliver coil (left) and texture of the recycled staple fiber sliver (right).

\subsection{Production of Test Specimens}

To fabricate the test specimen, recycled carbon fiber sliver and polyamide matrix granules were processed via injection molding compounding on an IMC 200-1400 C2, KraussMaffei Group, Munich. The fiber content can be adjusted by the number and fineness of the fibers fed into the direct feed module of the twin-screw extruder of the IMC and by the screw speed $n$ and the mass throughput $\dot{m}$ of the compounder. The theoretical fiber content $\varphi$ is calculated according to Equation (1), as described in the documentation of the IMC provided by KraussMaffei:

$$
\varphi=\frac{x \cdot S D F \cdot n \cdot k}{(x \cdot S D F \cdot n \cdot k)+\dot{m}} ; I P F=d_{f} \cdot U \cdot 60, U=d_{s i} \cdot(1+k) \cdot \pi,
$$

where $x$ corresponds to the number of rovings (in the case of this study, slivers) used in the feed module, $I P F$ is the initial throughput factor, $k$ is a correction factor in calculating the actual screw circumference $U$ from the inner screw diameter $d_{s i}$, and $d_{f}$ is the fiber mass per kilometer in tex $(\mathrm{g} / 1000 \mathrm{~m})$. 
To produce test specimens with a fiber content of $20 \%$ in the IMC, for example, the screw speed was set to $120 \mathrm{~min}^{-1}$, the mass throughput to $4 \mathrm{~kg} / \mathrm{h}$, and rovings with a fineness of $2.4 \mathrm{~g} / \mathrm{m}$ were used. By increasing the screw speed to $160 \mathrm{~min}^{-1}$ and reducing the mass throughput to $3 \mathrm{~kg} / \mathrm{h}$, a fiber content of $30 \%$ was achieved.

To further compare the results for recycled carbon fibers, test specimens with glass fiber rovings from Johns Manville, Denver, CO, USA, were also produced. The roving type E-glass PR 4402400871 (StarRov ${ }^{\circledR}$ LFTPlus) was adapted for processing with polyamide matrices with a silane sizing.

\subsection{Characterization of Test Specimens}

The characterization of fiber-reinforced plastics was carried out with classical methods to determine mechanical properties. The tensile tests, according to ISO 527, were performed by a universal testing machine type 1455 from Zwick GmbH and Co. KG, Ulm, Germany on the injection-molded basic specimens of type $1 \mathrm{~A}$. The bending properties were determined on the same machine, according to ISO 178. Seven to ten test specimens per mixing ratio were tested and statistically evaluated.

Tests such as the determination of fiber content (ISO 1172 method A), fiber length (ISO 22314), and fiber-matrix adhesion were also carried out. Due to the limited resources, complexity, and time consumption involved in carbon fiber length determination in an injection molded part using a solvolysis method, only two test specimens were measured: specimen one with a fiber content of $27 \mathrm{wt}-\%\left(\dot{m}=3 \mathrm{~kg} / \mathrm{h}, n=300 \mathrm{~min}^{-1}\right)$ and specimen two with a fiber content of $31 \mathrm{wt}-\%(\dot{m}=3 \mathrm{~kg} / \mathrm{h}$, $n=350 \mathrm{~min}^{-1}$ ). A specimen made of virgin fiber roving with a fiber content of $26 \mathrm{wt}-\%$ was also measured for comparison.

The single fiber length of the sliver was determined according to the standards DIN 53,803 and DIN 53808-1. For this purpose, 150 individual fibers were randomly and carefully removed from the fiber sample by hand and measured under a magnifying glass using a ruler.

\subsection{Summary of the Production Steps}

In the following section, the test evaluation is presented. Below is a short summary of the production process. The production cycle basically contains two steps:

- A staple fiber hybrid sliver, containing recycled carbon fibers (product scraps) and recycled PA6 fibers, is created and analyzed. Since product scraps are used, no additional sizing is applied to the fibers, and no information about the previous sizing is available.

- $\quad$ An IMC then produces recycling fiber-reinforced parts for evaluation. Virgin PA6 is mixed with recycled PA6 in various ratios. The sliver is added to the matrix via a direct feed module.

\section{Results}

\subsection{Sliver Characterization}

Throughout the textile process, the fiber length and mixing ratio were measured to continuously assess the individual process steps and changes in the material. During the production of the sliver, mechanical work was applied to open and align the fibers, resulting in a shortening of the carbon fibers, as shown in Figure 7. Despite ongoing optimization of all textile process steps, the carbon fibers were shortened by $20 \%$ from the raw material to the sliver regarding the median fiber length. 


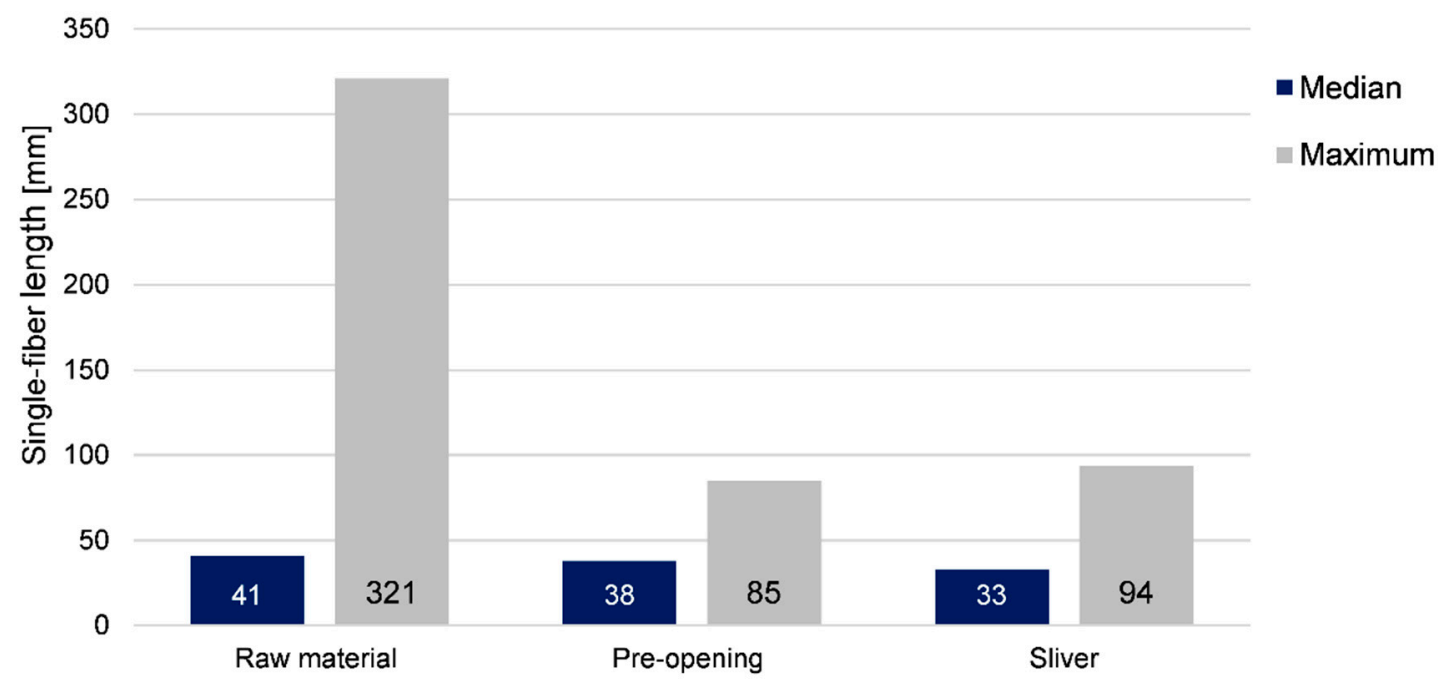

Figure 7. Change of the average and maximum carbon fiber length through the sliver production process.

To measure the single-fiber length, the examined carbon fibers were laid out on black velvet, covered by a glass plate, and placed under a magnifying glass with illumination. Using tweezers and fingers, the carbon fibers were carefully removed from the fiber agglomeration. The sliver in particular, had to be delicately dissolved by hand to remove the carbon fibers without damage. For this reason, the resulting single-fiber length is questionable. The tendency of a fiber to shorten after each processing step, however, was assumed to be correct.

Even slight mechanical processing of the fibers during pre-opening resulted in shortening, especially for the longest carbon fibers. A further reduction of the carbon fiber length was due to the mechanical processing of the fibers in the carding machine. Overall, the processing of carbon fibers results in a more uniform fiber length distribution, which can be beneficial for further processing and lead to stable process conditions.

Figure 8 shows the change in the mixing ratio over the sliver production process. The development of fiber dust in the carding process can be detected by measuring a change in the mixing ratio. While the pre-opening, which included measurement inaccuracies due to the sample size, did not lead to a change in the mixing ratio, the mechanical processing of the carbon fibers in the carding machine caused fiber breakage, and thus, fiber dust, decreasing the carbon fiber fraction. The further reduction of the carbon content was due to the removal of fiber dust from the sliver. Overall, a reduction of the carbon content by $7 \%$ resulted during manufacturing.

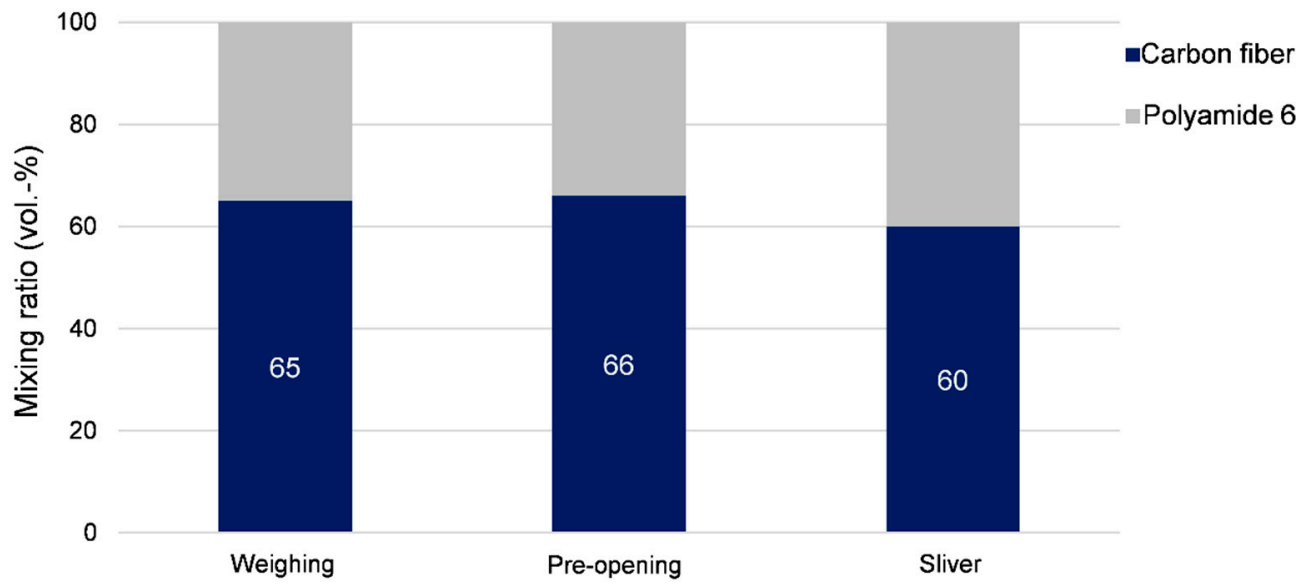

Figure 8. Change of the mixing ratio over the sliver production process. 


\subsection{Preliminary Investigations of Fiber Content in Relation to the Process Settings}

In a previous study, comparatively strong results were achieved when processing glass fibers in a single-stage process via the direct fiber feed module [10], and the fiber content was predicted successfully. Hitherto, carbon fibers had never been processed in a single-stage process using a direct fiber feed module, so this study investigated the transferability of the results to the processing of recycled carbon fibers. Therefore, the settings of speed and mass throughput at the IMC for a direct fiber feed of carbon fibers had to be determined in preliminary tests. To ensure comparability with previous tests of glass-fiber-reinforced recycled polyamide [10], carbon fiber contents of $20 \mathrm{wt}-\%$ and $30 \mathrm{wt}-\%$ were targeted.

Contrary to the use of virgin carbon fiber rovings, it was not yet known whether the processing settings of the recycled carbon fibers via the staple-fiber sliver could reliably be determined with the calculation model for the direct fiber feed module. Due to its hybrid structure, the carbon fiber content of the sliver is only roughly $60 \mathrm{wt}-\%$. In addition, the low consolidated structure (low tex value) of the sliver presented difficulty. Hence, a high sliver throughput was needed, requiring high screw speeds, which could increase fiber slippage and thus reduce the fiber content. Therefore, three setting approaches for the sliver were attempted in the preliminary tests. The selected test settings are shown in Table 3.

Table 3. Settings of the preliminary tests.

\begin{tabular}{cccc}
\hline Type of Fiber & $\begin{array}{c}\text { Mass throughput } \\
\dot{\boldsymbol{m}} \mathbf{( k g / h )}\end{array}$ & Screw Speed $\boldsymbol{n}$ (rpm) & $\begin{array}{c}\text { Calculated Fiber } \\
\text { Content (wt-\%) }\end{array}$ \\
\hline \multirow{3}{*}{ Reinforced Carbon Fiber } & 4 & 160 & 30 \\
& 4 & 100 & 25 \\
Recycled Staple Fiber & 5 & 100 & 20 \\
Sliver & 3 & 200 & - \\
& 3 & 300 & - \\
\hline
\end{tabular}

The results of the fiber content measurements of the preliminary tests in Figure 9 show that the calculation model is also applicable to the processing of (virgin) carbon fiber rovings, in general. For the sliver, in contrast, the mass throughput of $\dot{m}=3 \mathrm{~kg} / \mathrm{h}$ and a screw speed of $n=300 \mathrm{~min}^{-1}$ yielded a fiber content of approximately $20 \mathrm{wt}-\%$, which is lower than predicted. Since the screw speed of $n=400 \mathrm{~min}^{-1}$ induced a fiber content that was too high, the speed for the further investigation was set to $n=350 \mathrm{~min}^{-1}$ for a mass throughput of $\dot{m}=3 \mathrm{~kg} / \mathrm{h}$.

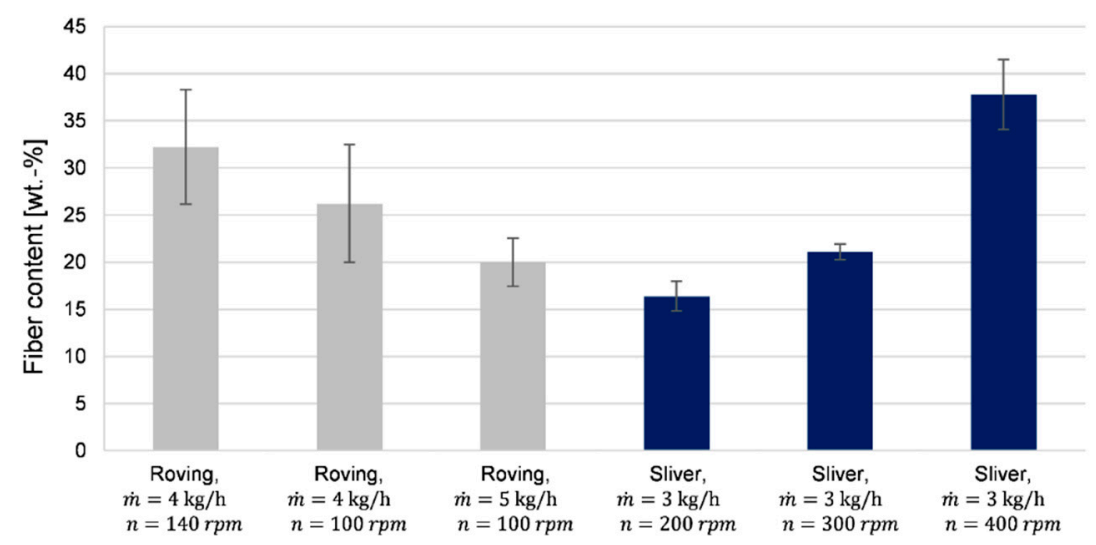

Figure 9. Fiber content in preliminary tests with carbon fiber roving and recycled staple fiber sliver. 
In general, the deviations of the measured values were quite large. This could have been due to the unsteady sliver formation process. High fluctuations were observed during the single-stage process with the glass fibers as well, which could be attributed to the IMC [10].

\subsection{Fiber Content}

Figure 10 shows the averaged fiber contents of the different mixtures from the single-stage process. When processing the sliver, the calculated settings did not lead to the desired results. Nearly all mixtures exhibited higher fiber content values than the calculated values according to Equation (1). In particular, for the calculated fiber content of $20 \mathrm{wt}-\%$, all measured values were above $30 \mathrm{wt}-\%$. In some cases, this discrepancy was even larger at higher speeds. Overall, the fiber contents showed high deviations and inconsistent behavior.

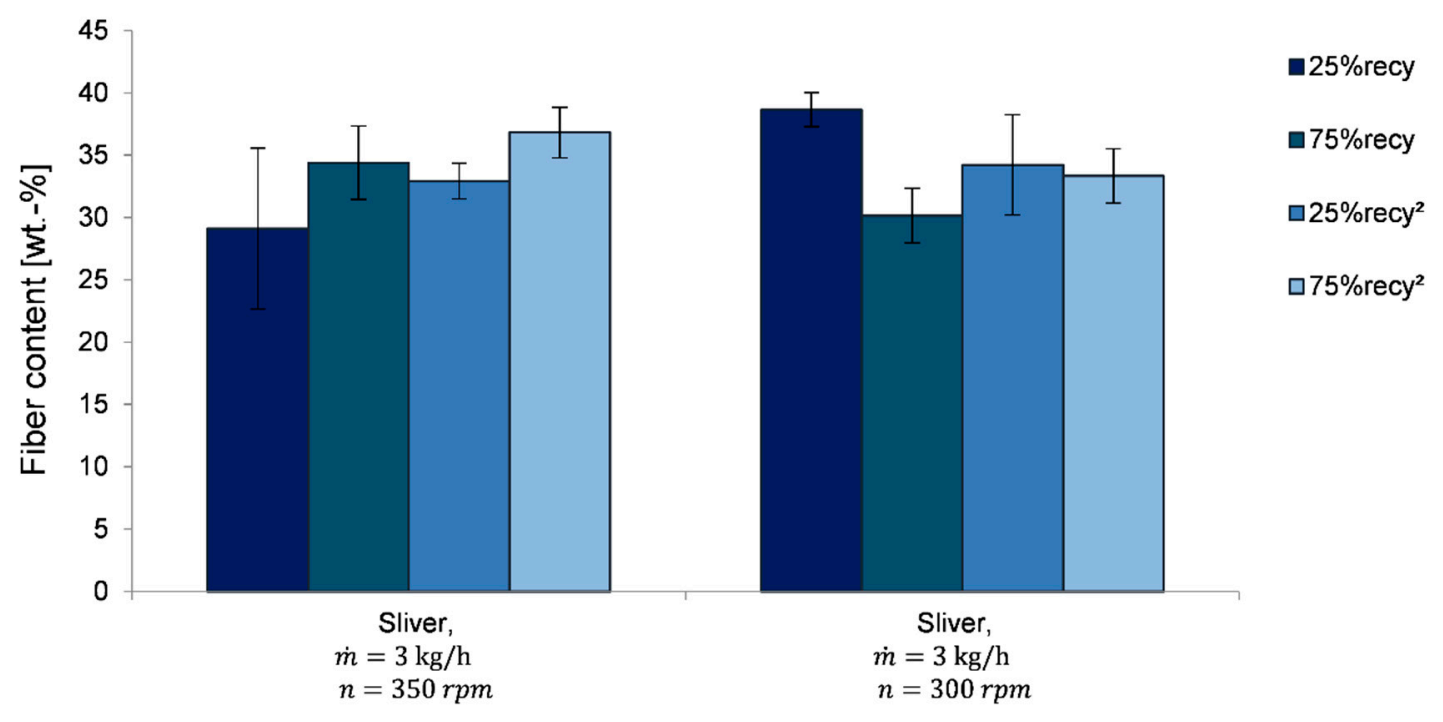

Figure 10. Averaged fiber content of the recycled staple fiber sliver with varying recycling content of the matrix.

The deviation of fiber content was due to the sliver formation process. Further, the feeding of the sliver into the IMC led to difficulties during processing. The sliver did not have a homogeneous width (see Figure 6) and was stretched irregularly when entering the extruder because of its unconsolidated texture. As a result, the sliver was not drawn in continuously and sometimes even tore during processing, resulting in an uneven fiber distribution in the melt. Further, varying process parameters can additionally cause small fluctuations in the fiber content. For example, friction occurs during fiber draw-in at the extruder, which counteracts the fiber draw-in force and can thus have effects on fiber retention and length. The friction is influenced by the roving and roving guide type, bobbin winding, screw geometry, and physical properties of the melt.

An analysis of the recycling content in the matrix material shows no significant influence on the fiber content. The scatter of the measured fiber content values was large. Therefore, the influence of process fluctuations on fiber content is assumed to be strong. In previous work with glass fibers [10], it was also shown that there is no clear correlation between fiber content and recycling rate. Only in the case of twice-recycled material could a dependency be determined. The values obtained here, however, show only small deviations with no statistical significance, even for twice-recycled material.

In summary, the settings calculated according to Equation (1) in the single-stage process with the sliver did not lead to the desired results. The calculation model for the direct fiber feed in a single-stage process cannot, therefore, be applied to the staple fiber sliver made of recycled carbon fibers. 


\subsection{Fiber Length}

The fiber lengths of two test specimens were measured: specimen one with a fiber content of $27 \mathrm{wt}-\%\left(\dot{m}=3 \mathrm{~kg} / \mathrm{h}, n=300 \mathrm{~min}^{-1}\right)$ and specimen two with a fiber content of $31 \mathrm{wt}-\%(\dot{m}=3 \mathrm{~kg} / \mathrm{h}$, $n=350 \mathrm{~min}^{-1}$ ). The results were compared to a specimen made of virgin fiber roving with a fiber content of $26 \mathrm{wt}-\%$. Analyses of the weight-averaged fiber lengths their distributions were based on the ISO 22,314 standard.

Table 4 shows the average fiber lengths of the different mixtures of the single-stage process. Overall, fiber lengths between 200 and $330 \mu \mathrm{m}$ were obtained. When comparing the different types of carbon fibers used with an analogous adjustment of the fiber content, longer fibers were observed in the test specimens from rovings. The average fiber length values were about $35 \%$ higher.

Table 4. Settings of the preliminary tests.

\begin{tabular}{ccc}
\hline Type of Fiber & Fiber Content (wt-\%) & Averaged Fiber Length (mm) \\
\hline Roving & 26 & 0.33 \\
Sliver & 27 & 0.20 \\
Sliver & 31 & 0.32 \\
\hline Glass Fiber & 23 & 1.06 \\
Glass Fiber & 31 & 0.74 \\
\hline
\end{tabular}

When comparing the fiber contents of the two test specimens made of sliver, the higher fiber content of $31 \mathrm{wt}-\%$ yielded significantly longer fibers compared to the lower fiber content of $27 \mathrm{wt}-\%$. The comparison of the fiber length distribution also shows that a fiber content of $31 \mathrm{wt}-\%$ leads to significantly longer fibers of up to $5 \mathrm{~mm}$. At a fiber content of $27 \mathrm{wt}-\%$, however, a maximum fiber length of $0.8 \mathrm{~mm}$ was observed.

Investigations with glass fibers utilizing a direct fiber feed module in the single-stage process, on the other hand, have shown that a higher fiber content increases the fiber degradation [10]. This effect is explained by the associated higher screw speed and the resulting increase in shear forces in the melt. The reduction of the mass flow rate led to an increased shear energy input, and thus, additional stress to the fibers. Additionally, an increase in the material residence time in the mixing zone could lead to a further reduction in fiber length. Likewise, as the fiber content increases, the fiber length decreases owing to the intensive fiber-fiber interaction [10]. Nonetheless, findings in the literature are contradictory in terms of the influence of the screw speed on fiber length. Higher screw speeds can also result in longer fibers because of the reduced melt viscosity and dwell time, as described in $[37,38]$.

The fibers of the (virgin) glass-fiber-reinforced test specimens produced in the single-stage process were significantly longer (an average of $0.74 \mathrm{~mm}$ ) than the fibers of the carbon-fiber-reinforced test specimens made of staple fiber sliver (Table 4). The shorter fiber lengths of the recycled carbon fiber test specimens can be attributed to the carbon fibers being thinner and more brittle than glass fibers. It has also been observed in the literature that when comparing short-fiber-reinforced composites with a fiber content of $30 \mathrm{wt}-\%$, the glass-fiber-reinforced test specimens have, on average, significantly longer fibers [39]. Dependence of the recycling fraction and fiber length cannot be determined owing to the small number of samples investigated.

In summary, the average fiber length of the carbon fibers was $0.3 \mathrm{~mm}$. Shorter fibers were measured at a lower fiber content of $27 \mathrm{wt}-\%$, whereas a higher fiber content of $31 \mathrm{wt}-\%$ resulted in longer fibers. The influence of the recycled content of the matrix on carbon fiber length could not be determined due to the small number of samples measured.

Since only representative samples were evaluated, the actual fiber length of each test specimen is unknown. The results are intended to test the possibility of fiber length measurement to this extent and to show a trend in fiber length and fiber-length distribution. 


\subsection{Mechanical Properties}

Figure 11 shows the average Young's moduli of the test specimens from the single-stage process. The test specimens with a fiber content of $27 \mathrm{wt}-\%$ had similar values to those of the test specimens with a fiber content of $30 \mathrm{wt}-\%$, roughly $25,000 \mathrm{MPa}$. This suggests an overall good performance of the material compared to the recycling routes summarized by Pimenta [2], especially considering the advantages of the injection molding process compared to bulk molding compound compression or compression molding of non-wovens, which are other solutions for discontinuous fiber processing described in the literature. Pimenta stated that Young's moduli of $20 \mathrm{GPa}, 5-30 \mathrm{GPa}$, and 14-16 GPa were reached for bulk molding compounds, non-wovens, and injection molded parts, respectively [2].

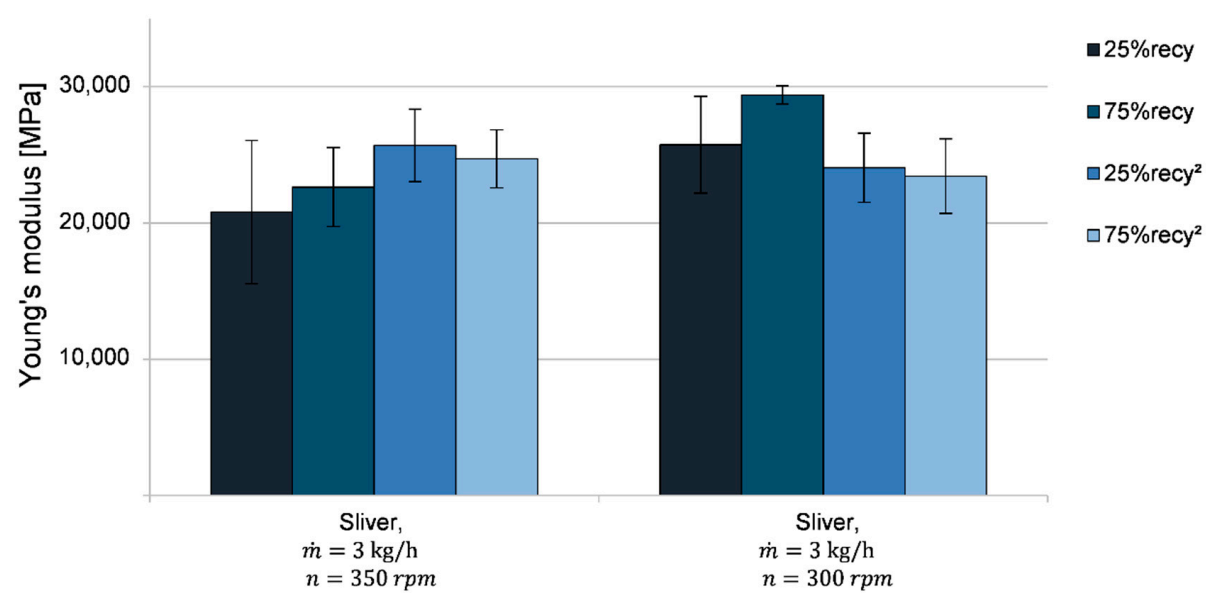

Figure 11. Young's moduli of specimens produced in the single-stage process with varying recycling content of the matrix.

When the results of the mechanical test are compared with those of the fiber content measurements presented above, a certain correlation can be established. Figure 12 shows the average Young's moduli of the test specimens and their average fiber contents. Overall, parallels can be seen between Young's modulus and fiber content, as expected.

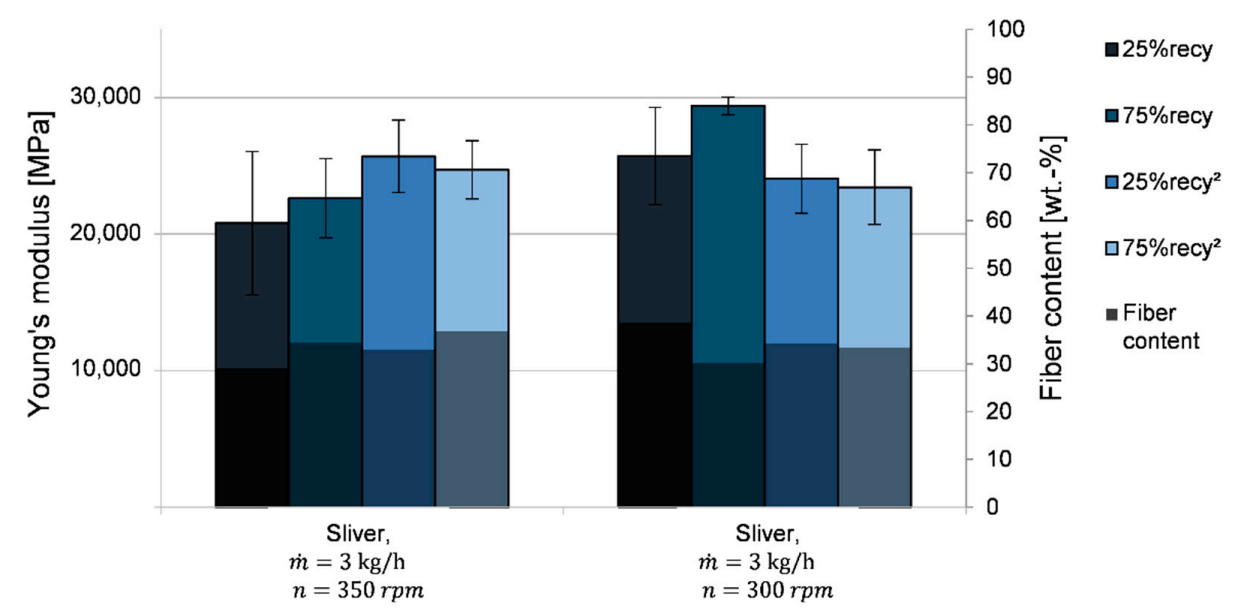

Figure 12. Young's moduli of specimens produced in the single-stage process with varying recycling content and corresponding fiber content of the matrix.

However, the dependence of Young's modulus on the recycled content of the matrix cannot be determined. The double reuse of PA6 does not lead to any significant effects. This means that the recycling-related impairments of the plastic have no apparent effect on the tensile modulus. Instead, the material parameter is primarily determined by the fiber content. 
The standard deviations of Young's modulus are very high, up to 13\%, due to processing instabilities caused by the IMC and the resulting scattering of fiber content within a batch. As previously explained, there were irregularities in the feeding of sliver, which led to fluctuations of the fiber content in the melt.

When Young's moduli of the carbon-fiber-reinforced recycled parts tested are compared to those of the glass fiber-reinforced plastic parts produced under almost identical conditions, an influence of the type of reinforcing fiber on the part can be clearly established. In Figure 13, glass-fiber-reinforced parts produced in the same process exhibit Young's moduli of approximately 10,000 MPa, nearly half of that of recycled carbon-fiber-reinforced parts. The use of carbon fibers, therefore, leads to significantly higher stiffness of the part, even though the length of the recycled carbon fibers is significantly shorter than the length of the glass fibers.

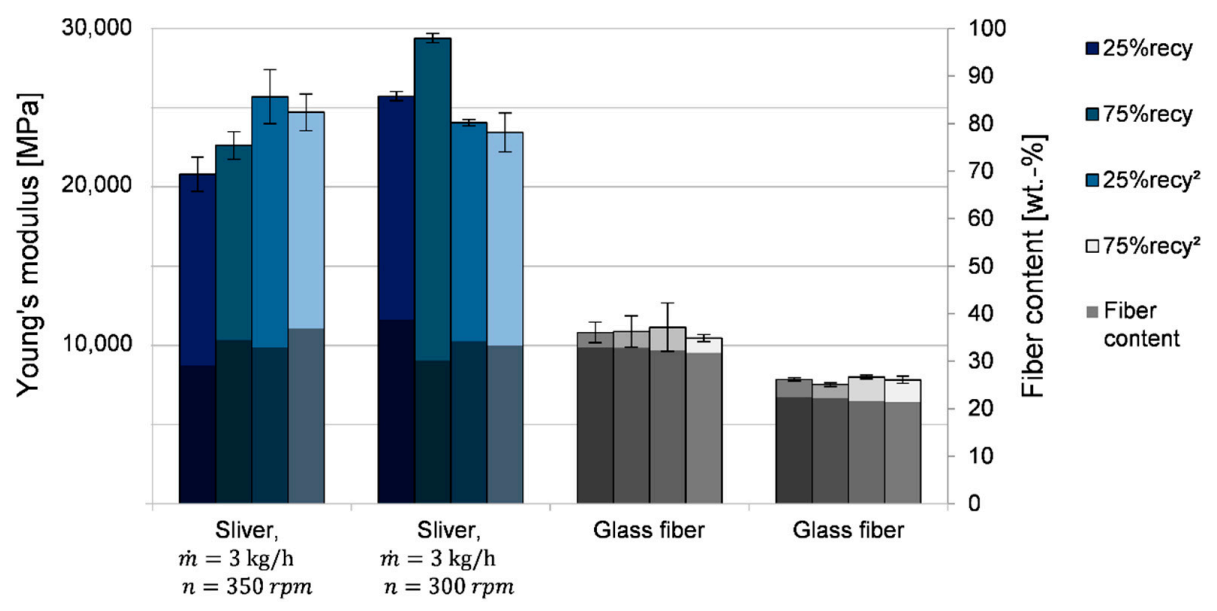

Figure 13. Young's moduli of specimens produced in the single-stage process with varying recycling content and corresponding fiber content of the matrix compared to parts produced with virgin glass fiber rovings and similar fiber content.

To further evaluate the mechanical properties, the tensile strength was determined. The results are shown in Figure 14. As expected, the tensile strength is also dependent on the fiber content. Similar to the modulus of elasticity, a correlation with the fiber content can be observed for the tensile strength as well.

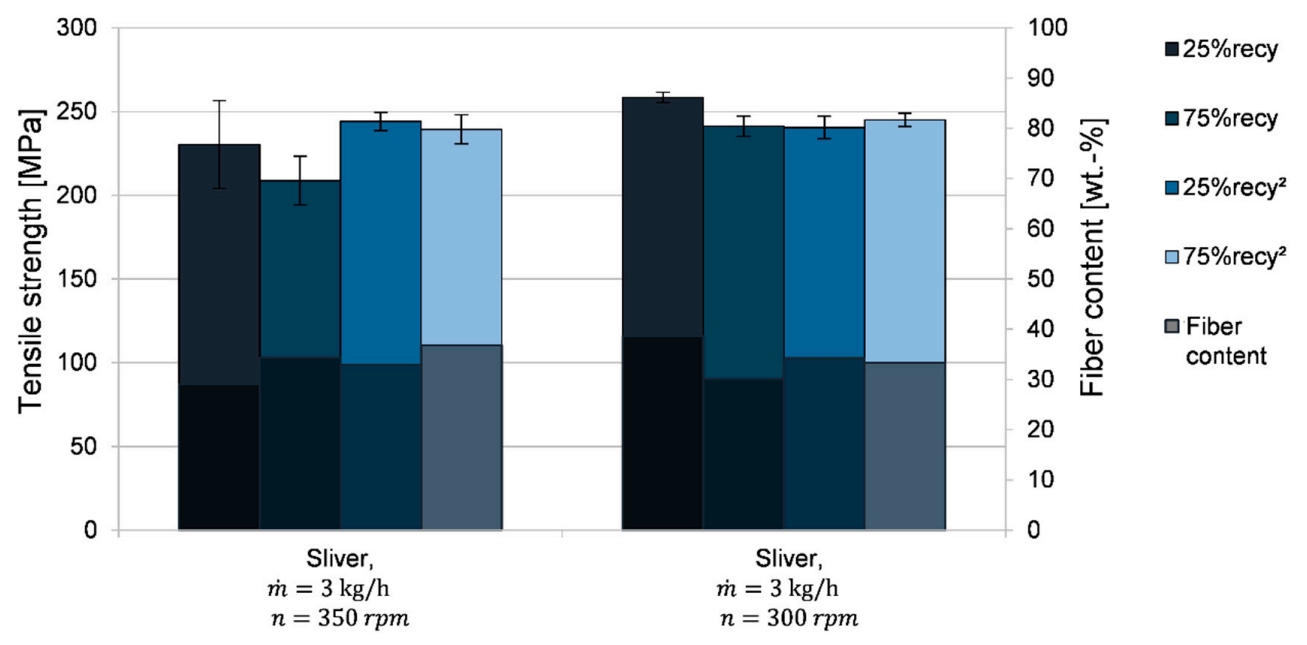

Figure 14. Young's moduli of specimens produced in the single-stage process with varying recycling content and corresponding fiber content of the matrix.

For the comparison of the two different fiber types, the average tensile strengths of the glass fiber specimens and the sliver specimens are shown in Figure 15. As with Young's modulus, the test 
specimens from the recycled carbon fiber sliver showed significantly higher tensile strengths compared to the glass fiber specimens, confirming previous results.

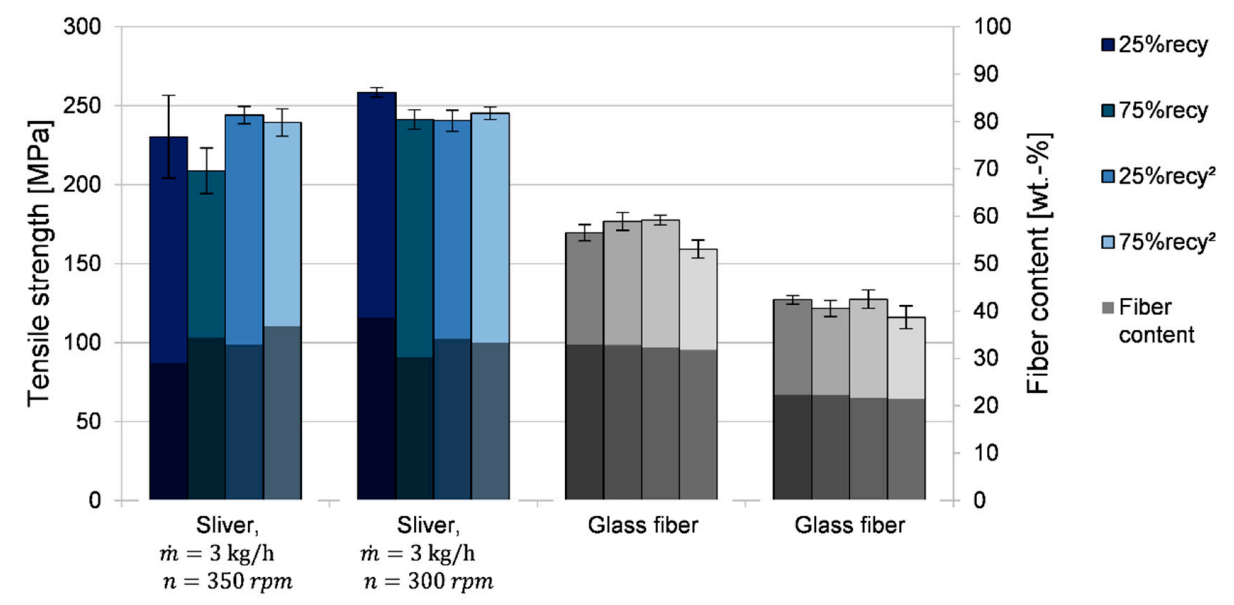

Figure 15. Tensile strengths of specimens produced in the single-stage process with varying recycling content and corresponding fiber content of the matrix compared to parts produced with virgin glass fiber rovings and similar fiber content.

The analyses of the elongation at break, the impact strength, and the flexural modulus and strength showed similar results and will not be presented in this study to avoid redundancy.

\section{Summary and Outlook}

In this study, a novel method to recycle carbon fibers efficiently while preserving fiber length was investigated. A hybrid sliver with 60 vol- $\%$ carbon fiber content was produced from recycled carbon and PA6 fibers. A shortening of the carbon fiber of about $50 \%$ resulted after the entire process. At the same time, a narrowing of the fiber length distribution could be observed. The sliver was then used for the production of test specimens on an IMC utilizing a direct fiber feed module.

The feeding of the staple fiber sliver into the melt was challenging. The sliver stretched unevenly and sometimes tore. The predicted fiber content could not be achieved in the single-stage process. In fact, the fiber contents were higher than the calculated values and had high fluctuations. The fiber content measurements do not show a clear dependency on the recycled content of the matrix.

A fiber length measurement was performed on three random samples. The results show an increasing fiber length with increasing fiber content. Fibers of parts made of virgin carbon fiber rovings were longer than those of the recycled carbon fiber sliver.

Tensile tests were carried out to characterize the mechanical properties. Overall, very good mechanical characteristics could be achieved. Correlations between the actual fiber content and the mechanical properties were determined. The higher the fiber content, the better the mechanical properties. Large deviations of the measured values were observed. Furthermore, it can be stated that the recycling-related impairment of the matrix has no effect on the modulus of elasticity, tensile strength, flexural strength, or impact strength.

When comparing the recycled carbon-fiber-reinforced test specimens with the glass fiber test specimens, a clear dependence of the mechanical characteristics on the type of reinforcement fiber was determined. The sliver test specimens all achieved significantly higher results, although the recycled carbon fibers were significantly shorter than the glass fibers.

The results show that desirable mechanical properties can be achieved in principle when recycled carbon fibers are processed in the form of a staple fiber sliver. However, it is questionable whether the processing of staple fiber sliver allows a reproducible adjustment of the fiber content, and thus, predictability of the properties. The loose structure of the sliver causes difficulties with drawing the fibers in the process evenly. The use of the hybrid yarn could simplify the drawing of the recycled fibers, 
as the strength of the yarn is considerably higher. Thus, a yarn spinning process was developed to further process the sliver before injection molding. This further reduces the fiber content but improves the fiber distribution. Fewer process fluctuations might be reached this way.

Author Contributions: Conceptualization, J.W. and S.B.; methodology, J.W. and J.R.; validation, J.R.; investigation, J.W. and J.R.; resources, G.T.G. and C.B.; writing—original draft preparation, J.W. and J.R.; writing-review and editing, S.B., G.T.G. and C.B.; visualization, J.R. and S.B.; supervision, G.T.G. and C.B.; project administration, J.W. and S.B.; funding acquisition, G.T.G. and C.B.; All authors have read and agreed to the published version of the manuscript.

Funding: This research was funded by the Baden-Württemberg-Stiftung, grant number MAT0005.

Conflicts of Interest: The authors declare no conflict of interest.

\section{References}

1. Meng, F.; Olivetti, E.; Zhao, Y.; Chang, J.C.; Pickering, S.J.; McKechnie, J. Comparing Life Cycle Energy and Global Warming Potential of Carbon Fiber Composite Recycling Technologies and Waste Management Options. ACS Sustain. Chem. Eng. 2018, 6, 9854-9865. [CrossRef]

2. Pimenta, S.; Pinho, S.T. Recycling carbon fibre reinforced polymers for structural applications: Technology review and market outlook. Waste Manag. 2011, 31, 378-392. [CrossRef] [PubMed]

3. Pickering, S.J.; Liu, Z.; Turner, T.; Wong, K. Applications for carbon fibre recovered from composites. Iop Conf. Ser. Mater. Sci. Eng. 2016, 139, 012005. [CrossRef]

4. Oliveux, G.; Dandy, L.O.; Leeke, G.A. Current status of recycling of fibre reinforced polymers: Review of technologies, reuse and resulting properties. Prog. Mater. Sci. 2015, 72, 61-99. [CrossRef]

5. Pickering, S. Recycling technologies for thermoset composite materials-current status. Compos. Part A Appl. Sci. Manuf. 2006, 37, 1206-1215. [CrossRef]

6. Schürmann, H. Konstruieren mit Faser-Kunststoff-Verbunden; Springer Science and Business Media LLC: Berlin/Heidelberg, Germany, 2005.

7. Truckenmüller, F. Direktverarbeitung von Endlosfasern auf Spritzgießmaschinen. Möglichkeiten und Grenzen. Dissertation, Universität Stuttgart, Stuttgart, Germany, 1996.

8. Widmayer, S.; Fritz, H.-G.; Bonten, C. Spritzgießcompoundieren: Feuchte vereinzelt Naturfasern. Kunststoffe Munchen. 2012, 12, 71-74.

9. Willems, F.; Bonten, C. Influence of processing on the fiber length degradation in fiber reinforced plastic parts. In Proceedings of the 34th International Conference of the Polymer Processing Society, Gratz, Austria, 14 December 2015; AIP Publishing: Melville, NY, USA, 2016; Volume 1779, p. 020003.

10. Wellekötter, J.; Christian, B. Comparison of fiber-reinforced recycled polyamide in single stage and two stage injection molding. Polym. Compos. 2018, 40, 1731-1739. [CrossRef]

11. Bonten, C. Plastics Technology_Introduction and Fundamentals; Hanser: Munich, Germany, 2019.

12. Witten, E.; Kraus, T.; Kühnel, M. Composites-Marktbericht 2016. Available online: https://elib.dlr.de/106030/ (accessed on 15 September 2020).

13. Gardiner, G. Closing the CFRP lifecycle loop. Recycled carbon fiber update. Compos. World 2014, $28-33$.

14. Lefeuvre, A.; Garnier, S.; Jacquemin, L.; Pillain, B.; Sonnemann, G. Anticipating in-use stocks of carbon fiber reinforced polymers and related waste flows generated by the commercial aeronautical sector until 2050. Resour. Conserv. Recycl. 2017, 125, 264-272. [CrossRef]

15. Pillain, B.; Loubet, P.; Pestalozzi, F.; Woidasky, J.; Erriguible, A.; Aymonier, C.; Sonnemann, G. Positioning supercritical solvolysis among innovative recycling and current waste management scenarios for carbon fiber reinforced plastics thanks to comparative life cycle assessment. J. Supercrit. Fluids 2019, 154, 104607. [CrossRef]

16. Rybicka, J.; Tiwari, A.; Leeke, G.A. Technology readiness level assessment of composites recycling technologies. J. Clean. Prod. 2016, 112, 1001-1012. [CrossRef]

17. Witik, R.A.; Teuscher, R.; Michaud, V.; Ludwig, C.; Manson, J.-A.E. Carbon fibre reinforced composite waste: An environmental assessment of recycling, energy recovery and landfilling. Compos. Part. A Appl. Sci. Manuf. 2013, 49, 89-99. [CrossRef] 
18. Naqvi, S.; Prabhakara, H.M.; Bramer, E.; Dierkes, W.; Akkerman, R.; Brem, G. A critical review on recycling of end-of-life carbon fibre/glass fibre reinforced composites waste using pyrolysis towards a circular economy. Resour. Conserv. Recycl. 2018, 136, 118-129. [CrossRef]

19. Wong, K.; Rudd, C.; Pickering, S.; Sandinge, A. Composites recycling solutions for the aviation industry. Sci. China Ser. E Technol. Sci. 2017, 60, 1291-1300. [CrossRef]

20. Hofmann, M.; Gulich, B. Verarbeitung von rezyklierten Carbonfasern für die Herstellung von Verbundbauteilen. Light. Des. 2013, 6, 20-23. [CrossRef]

21. Jacob, A. Composites can be recycled. Reinf. Plast. 2011, 55, 45-46. [CrossRef]

22. Hengstermann, M.; Raithel, N.; Abdkader, A.; Hasan, M.; Cherif, C. Development of new hybrid yarn construction from recycled carbon fibers for high performance composites. Part-I: Basic processing of hybrid carbon fiber/polyamide 6 yarn spinning from virgin carbon fiber staple fibers. Text. Res. J. 2015, 86, 1307-1317. [CrossRef]

23. Longana, M.L.; Ong, N.; Yu, H.; Potter, K.D. Multiple closed loop recycling of carbon fibre composites with the HiPerDiF (High Performance Discontinuous Fibre) method. Compos. Struct. 2016, 153, $271-277$. [CrossRef]

24. Reichert, O.; Ausheyks, L.; Baz, S.; Hehl, J.; Gresser, G.T. Innovative rC Staple Fiber Tapes - New Potentials for CF Recyclates in CFRP through Highly Oriented Carbon Staple Fiber Structures. Key Eng. Mater. 2019, 809, 509-514. [CrossRef]

25. Tian, X.; Liu, T.; Wang, Q.; Dilmurat, A.; Li, D.; Ziegmann, G. Recycling and remanufacturing of 3D printed continuous carbon fiber reinforced PLA composites. J. Clean. Prod. 2017, 142, 1609-1618. [CrossRef]

26. Osswald, T.A.; Menges, G. Materials Science of Polymers for Engineers, 3rd ed.; Hanser: München, Germany, 2012.

27. Thomason, J. The influence of fibre length and concentration on the properties of glass fibre reinforced polypropylene: 5. Injection moulded long and short fibre PP. Compos. Part. A Appl. Sci. Manuf. 2002, 33, 1641-1652. [CrossRef]

28. Martens, H. Recyclingtechnik. Fachbuch für Lehre und Praxis; Spektrum: Heidelberg, Germany, 2011.

29. Johannaber, F.; Michaeli, W. Handbuch Spritzgießen, 2nd ed.; Hanser: München, Germany, 2004.

30. Maspoch, M.L.; Ferrando, H.E.; Velasco, J.I. Characterisation of filled and recycled PA6. Macromol. Symp. 2003, 194, 295-304. [CrossRef]

31. Henning, F.; Moeller, E. Handbuch Leichtbau. Methoden, Werkstoffe, Fertigung; Hanser: München, Germany, 2011.

32. Hopmann, C.; Michaeli, W. Einführung in die Kunststoffverarbeitung, 7th ed.; Hanser: München, Germany, 2015.

33. Wolters, L. (Ed.) Kunststoff-Recycling; Hanser: München, Germany, 1997.

34. Crespo, J.; Parres, F.; Peydro, M.; Navarro, R. Study of rheological, thermal, and mechanical behavior of reprocessed polyamide 6. Polym. Eng. Sci. 2012, 53, 679-688. [CrossRef]

35. Su, K.-H.; Lin, J.-H.; Lin, C.-C. Influence of reprocessing on the mechanical properties and structure of polyamide 6. J. Mater. Process. Technol. 2007, 192-193, 532-538. [CrossRef]

36. Formisano, B.; Göttermann, S.; Bonten, C. Recycling of cast polyamide waste on a twin-screw-extruder. In Proceedings of the 34th International Conference of the Polymer Processing Society, Lyon, France, 25-29 July 2016; AIP Publishing: Melville, NY, USA, 2016; Volume 140002.

37. Moritzer, E.; Heiderich, G.; Hirsch, A. Fiber length reduction during injection molding. In Proceedings of the AIP Conference 2055, Dresden, Germany, 27-29 June 2017; AIP Publishing: Melville, NY, USA, 2019.

38. Cieslinski, M. Using a Sliding Plate Rheometer to Obtain Material Parameters for Simulating Long Fiber Orientation in Injection Molded Composites. Ph.D. Thesis, Virginia Polytechnic Institute and State University, Blacksburg, VA, USA, 2015.

39. Sarasua, J.R.; Remiro, P.M.; Pouyet, J. The mechanical behaviour of PEEK short fibre composites. J. Mater. Sci. 1995, 30, 3501-3508. [CrossRef]

Publisher's Note: MDPI stays neutral with regard to jurisdictional claims in published maps and institutional affiliations. 